WHO ARE THE ESSENTIAL AND FRONTLINE WORKERS?

\author{
Francine D. Blau \\ Josefine Koebe \\ Pamela A. Meyerhofer \\ Working Paper 27791 \\ http://www.nber.org/papers/w27791 \\ NATIONAL BUREAU OF ECONOMIC RESEARCH \\ 1050 Massachusetts Avenue \\ Cambridge, MA 02138 \\ September 2020, Revised March 2021
}

The views expressed herein are those of the authors and do not necessarily reflect the views of the National Bureau of Economic Research.

NBER working papers are circulated for discussion and comment purposes. They have not been peer-reviewed or been subject to the review by the NBER Board of Directors that accompanies official NBER publications.

(C) 2020 by Francine D. Blau, Josefine Koebe, and Pamela A. Meyerhofer. All rights reserved. Short sections of text, not to exceed two paragraphs, may be quoted without explicit permission provided that full credit, including $\odot$ notice, is given to the source. 
Who are the Essential and Frontline Workers?

Francine D. Blau, Josefine Koebe, and Pamela A. Meyerhofer

NBER Working Paper No. 27791

September 2020, Revised March 2021

JEL No. J15,J16,J21

\begin{abstract}
$\underline{\text { ABSTRACT }}$
Identifying essential and frontline workers and understanding their characteristics is useful for policymakers and researchers in targeting social insurance and safety net policies in response to the COVID-19 crisis and allocating scarce resources like personal protective equipment (PPE) and vaccines. We develop a working definition and provide data on the demographic and labor market composition of these workers. We first apply the official industry guidelines issued by the Department of Homeland Security (DHS) in March 2020 to microdata from the 2018 and 2019 American Community Survey to identify essential workers regardless of actual operation status of their industry. We then use the feasibility of work from home in the worker's occupation group (Dingel and Neiman 2020) to identify those most likely to be frontline workers who worked inperson early in the COVID-19 crisis in March/April 2020. In a third step, we exclude industries that were shutdown or running under limited demand at that time (Vavra, 2020). We find that the broader group of essential workers comprises a large share of the labor force and tends to mirror its demographic and labor market characteristics. In contrast, the narrower category of frontline workers is, on average, less educated, has lower wages, and has a higher representation of men, disadvantaged minorities, especially Hispanics, and immigrants. These results hold even when excluding industries that were shutdown or operating at a limited level. Results for essential and frontline workers are similar when accounting for changes in the federal guidelines over time by using the December 2020 guidelines which include a few additional groups of workers, including the education sector.

Francine D. Blau

ILR School

Cornell University

268 Ives Hall

Ithaca, New York 14853-3901 and

NBER

fdb4@cornell.edu

Josefine Koebe

Department Education and Family

DIW Berlin

Mohrenstr. 58

10117 Berlin

Germany

jkoebe@diw.de

Pamela A. Meyerhofer

Department of Agricultural Economics and Economics

MSU- Bozeman

PO Box 172920

Bozeman, MT 59715

pamela.meyerhofer@montana.edu
\end{abstract}




\title{
Who are the Essential and Frontline Workers?
}

\author{
Francine D. Blau (Cornell University, NBER, DIW, IZA, CESifo) \\ Josefine Koebe (DIW Berlin / Universität Hamburg) \\ Pamela A. Meyerhofer (Montana State University)
}

March 2021

\begin{abstract}
Identifying essential and frontline workers and understanding their characteristics is useful for policymakers and researchers in targeting social insurance and safety net policies in response to the COVID-19 crisis and allocating scarce resources like personal protective equipment (PPE) and vaccines. We develop a working definition and provide data on the demographic and labor market composition of these workers. We first apply the official industry guidelines issued by the Department of Homeland Security (DHS) in March 2020 to microdata from the 2018 and 2019 American Community Survey to identify essential workers regardless of actual operation status of their industry. We then use the feasibility of work from home in the worker's occupation group (Dingel and Neiman 2020) to identify those most likely to be frontline workers who worked in-person early in the COVID-19 crisis in March/April 2020. In a third step, we exclude industries that were shutdown or running under limited demand at that time (Vavra, 2020). We find that the broader group of essential workers comprises a large share of the labor force and tends to mirror its demographic and labor market characteristics. In contrast, the narrower category of frontline workers is, on average, less educated, has lower wages, and has a higher representation of men, disadvantaged minorities, especially Hispanics, and immigrants. These results hold even when excluding industries that were shutdown or operating at a limited level. Results for essential and frontline workers are similar when accounting for changes in the federal guidelines over time by using the December 2020 guidelines which include a few additional groups of workers, including the education sector.
\end{abstract}




\section{INTRODUCTION}

The COVID-19 pandemic has required the identification of essential workers who are vital for the core functioning of societal infrastructure. Formation of policies to protect and meet the needs of these essential workers and to allocate scarce resources like personal protective equipment (PPE) and vaccines depends on knowing their composition and characteristics. However, identifying essential workers is not straightforward. The definition of essential work may differ by state or even locality and change rapidly over time. Moreover, the risk essential workers face is influenced by whether they are frontline workers who must provide their labor in person or whether they can work from home. As some industries, even those deemed essential, may at times be mostly shut down or facing steep decreases in demand, who is really at work also depends on the current shutdown or demand status of their industry.

We address these data issues to provide information on the characteristics of essential workers and, more specifically, frontline workers. We begin by applying the official industry guidelines issued by the Department of Homeland Security (DHS) Cybersecurity and Infrastructure Security Agency (CISA) in March 2020 to microdata from the 2018 and 2019 American Community Survey (ACS) to identify the broader group of essential workers. ${ }^{1}$ We then use data on the feasibility of work from home in the worker's occupation group (Dingel and Neiman 2020) to identify those most likely to be frontline workers. We find that the broader group of essential workers comprises a large share of the labor force and tends to mirror its demographic characteristics. In contrast, frontline workers are a less educated, lower wage group, with a higher representation of men, disadvantaged minorities, especially Hispanics, and

\footnotetext{
${ }^{1}$ Previous versions of this paper used 2017 and 2018 ACS data as the 2019 data was not available at the time.
} 
immigrants, on average. Both conclusions remain unchanged when excluding industries that were considered shutdown/diminished demand during the early stages of the COVID crisis (Vavra, 2020). Results for essential and frontline workers are similar when accounting for changes in the federal guidelines over time by using the December 2020 DHS guidelines which include a few additional groups of workers, including workers in the education sector.

\section{DATA AND METHODS}

A common and clear-cut definition of essential workers would facilitate the rapidly evolving social science literature on COVID-19. However, the designation of "essential” requires interpretation and depends on the policy context. We propose a three-step approach narrowing from essential industries to "frontline" workers to "frontline excluding shutdown industries", capturing those who provide their labor in person in active industries.

First, although various states and cities under lockdown have applied their own definitions of essential, the federal guidelines provide a logical starting point for an analysis of essential workers. Thus, we begin with the federal guidelines listing essential infrastructure workers during the COVID-19 epidemic who "protect their communities, while ensuring continuity of functions critical to public health and safety, as well as economic and national security” issued by the Department of Homeland Security (DHS) Cybersecurity and Infrastructure Security Agency (CISA) on March 28, 2020. ${ }^{2}$ We translate the 14 categories that are defined as essential critical infrastructure sectors into the North American Industry Classification System (NAICS), identifying 196 out of overall 287 industry categories as essential. By matching the qualitative information from the DHS into the NAICS 2017 four-digit

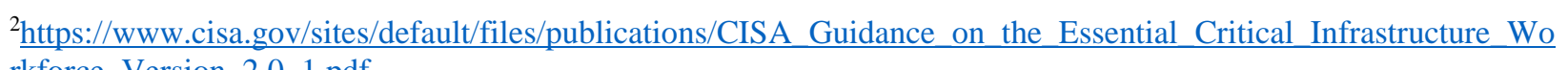
rkforce_Version_2.0_1.pdf 
industry classification, we attempt to refrain from subjective decision-making to the maximum extent possible by including all DHS-designated industries regardless of actual operation. This approximation of essential workers that we proposed in an Econofact memo (Blau et al., 2020) has also been used in Montenovo et al. (2020) and Gupta et al. (2020), both studying various COVID-19 repercussions on the labor market.

In a second step, we identify frontline workers by focusing on a subcategory of essential workers; those in occupation groups where a third or less of workers can feasibly work from home based on analysis by Dingel and Neiman (2020). They construct a work-from-home measure using pre-pandemic surveys from the Occupational Information Network that describe the typical experience of US workers to classify occupations at the major group (2 digit) level as able or unable to be done entirely from home. Making use of this measure allows us to focus on the composition and characteristics of frontline workers, a subset of essential workers who arguably face a higher level of risk of infection by providing their labor in person.

For the larger group of essential workers as well as the narrower subset of frontline workers, in a third step we additionally exclude industries that were shutdown or running under limited demand at the initial COVID-outbreak in March 2020 as identified by Vavra (2020), e.g. restaurants and other food services, traveler accommodation, air transportation, and a number of manufacturing industries.

Finally, we account for changes in the federal guidelines over time by comparing the groups defined above to the essential and frontline workers using guidelines issued by DHS CISA on December 16, 2020. ${ }^{3}$ The December 2020 DHS guidelines differ from those issued in

\footnotetext{
${ }^{3}$ The guidelines issued on December 16, 2020 (version 4) are identical to the August 2020 (version 3). The December guidelines are available here:
} 
March 2020 in adding the education sector, automobile dealers, other motor vehicle dealers, sporting good stores, and office supply stores. For the December 2020 breakdowns, we do not present results excluding shutdown industries as these were far fewer and more heterogeneous across states than they were in the early stages of the COVID-19 crisis in the U.S. in March 2020.

\section{FINDINGS}

We begin by presenting our findings using the March 2020 DHS guidelines. We then explore how our results are affected when updated based on the December 2020 DHS guidelines that include the education sector as well as some other additional categories.

\section{ESSENTIAL WORKERS: MARCH 2020}

Tables 1 and 2 show our results for essential and frontline workers at the aggregate level and, for frontline workers (our primary focus), separately at the major (2-digit) occupation level using the March 2020 definitions. Table 1 reports demographic characteristics and Table 2 reports labor market characteristics. As may be seen in the tables, essential workers, using this definition, comprise a large and varied group. Overall, they make up $70 \%$ of all workers (see Panel A in Tables 1 and 2). Women are well represented, although the female share (44\%) is somewhat lower than for the labor force as a whole (47\%). The other demographic characteristics of essential workers are also very similar to the general labor market on the aggregate level, although they are slightly more likely to be Hispanics or immigrants (foreign born) and have somewhat lower educational attainment (see Panel A in Table 1). The share of workers in predominantly $(70 \%+)$ female and predominantly (30\%-) male occupations (as

https://www.cisa.gov/sites/default/files/publications/ECIW_4.0_Guidance_on_Essential_Critical_Infrastructure_Wo rkers_Final3_508_0.pdf 
classified based on 4 digit occupational categories) is broadly similar between essential and all workers, although a somewhat larger share of essential workers are in predominantly male occupations as shown in Panel A of Table 2. Average wages of essential workers are virtually the same as for all workers and about the same share of essential workers as all workers earn low wages (in the bottom quartile of the overall wage distribution) and high wages (in the top quartile of the overall wage distribution). ${ }^{4}$ Taking into account the shutdown in the early stage of the crisis by excluding workers in affected industries does substantially reduce the estimated number of essential workers - to $60 \%$ of all workers; with average wages somewhat higher at $\$ 28.42$ (compared to \$27.05 for all workers). However, the demographic characteristics of essential workers are almost identical when excluding shutdown and limited demand industries.

\section{FRONTLINE WORKERS: MARCH 2020}

Frontline workers also vary but come disproportionately from socio-economically disadvantaged groups compared to the overall workforce (see Panel A in Table 1) and receive lower wages on average (Panel A in Table 2). Frontline workers include (but are not limited to) health care workers, protective service workers (police and EMS), cashiers in grocery and general merchandise stores, production and food processing workers, janitors and maintenance workers, agricultural workers, and truck drivers. Such workers constitute $43 \%$ of all workers. While women are overly represented in a number of specific frontline occupations, the average female share of frontline workers (39\%) is lower than for essential workers as a whole. Frontline workers are on average less well educated than all workers, with a higher share comprised of high school dropouts and a lower share having a college degree or higher. They also have a

\footnotetext{
${ }^{4}$ Wages are calculated by dividing annual wages by the product of usual hours per week worked and usual weeks per year worked. Wages are adjusted to 2019 dollars.
} 
considerably higher share of Hispanics and a somewhat higher share of Blacks. Immigrants are also disproportionately represented. Average wages of frontline workers (\$22.76) are lower than those of all workers and essential workers. A higher share of frontline workers earns low wages (in the bottom quartile) and a smaller share earns high wages (in the top quartile).

As would be expected, health care workers comprise an important share - $20 \%$ of frontline workers (see Panel B in Tables 1 and 2). Heath care workers include two major occupational categories: (i) healthcare practitioners and technical occupations and (ii) health care support. Practitioners and technical occupations, including doctors, registered nurses and pharmacists (among others), constitute the bulk of health care workers (69\%). They are a relatively highly educated, high paying group. While doctors are still a majority male occupation, overall, women comprise a majority of health care practitioners (75\%). Health support workers, such as nursing assistants and home health aides, constitute the remainder of health care workers. They are an even more heavily female group (86\%). In contrast to health care practitioners, they are a relatively less well educated and low wage group. Additionally, this group is majority nonwhite (55\%, including 25\% Black and 20\% Hispanic), immigrants are more heavily represented, and a substantial share are single mothers (23\% compared to $8 \%$ of frontline workers and all workers), suggesting they may face greater childcare burdens.

Sales and related occupations in essential industries also constitute a large share of frontline workers, $15 \%$. Women constitute a little under half of all workers in this occupation group, with a quarter of workers employed in predominantly female occupations. Overall, the average wage is slightly below that for all workers and an above average share earn wages in the 
bottom quartile. Almost a quarter of workers in this group are cashiers at essential retailers such as grocery stories and general merchandise stores. ${ }^{5}$

A number of heavily male, blue collar categories together constitute a large share of frontline occupations, including transportation and material moving occupations (14\%), production occupations (11\%), construction and extraction (10\%), building and grounds cleaning and maintenance (6\%), installation maintenance and repair (6\%), as well as farming, fishing and forestry occupations (2\%). Average wages for workers in these occupation groups are substantially below the average for all workers.

Protective service occupations constitute another crucial component of the frontline workforce, accounting for $4 \%$ of frontline workers. This is a primarily male category that earns about the same wage as the average for all workers.

If we take the estimates of closures and greatly reduced demand into account in measuring the frontline workforce (see Panel A in Tables 1 and 2), the estimated number of frontline workers is substantially reduced - to $34 \%$ of all workers. The percent female in the occupation declines slightly to $38 \%$ and average wages rise somewhat to $\$ 24.00$. However, our basic conclusion that the frontline group is disproportionately comprised of less educated, disadvantaged minority (especially Hispanic), and immigrant workers, earning below average wages and with a substantial share of workers in the bottom quartile, remains unchanged. Considering shutdown industries is of particular relevance for food preparation and serving occupations which potentially comprise a substantial share of frontline workers (10\%), but the smallest share (1.6\%) when taking shutdown into account (see Panel C in Tables 1 and 2). While

\footnotetext{
${ }^{5}$ In results not shown, cashiers are $72 \%$ female, $44 \%$ non-white, and $62 \%$ earn wages in the lowest quartile of all workers.
} 
some were working and taking the risk of exposure to clients at the early stage of the pandemic, the majority were unemployed. For both definitions this is a majority female and very a low wage occupation group on average.

\section{EDUCATORS}

The most significant change in the federal guidelines defining essential and thus also frontline workers in December 2020 was the addition of the education sector. Education moved almost universally to virtual instruction in the Spring of 2020, excluding educators from the essential and frontline definitions. By Fall 2020 and into early 2021 many, though far from all, districts and institutions had moved to mixed or in-person instruction. ${ }^{6}$ Table 3 shows the demographic and occupational characteristics of workers in education occupations by industry, within the education sector. We focus on this occupation category to provide results that are comparable to those for other occupation groups in Panel B of Tables 1 and $2 .{ }^{7}$

As may be seen in the table, educators are a sizable group, making up $14 \%$ of frontline workers and 6\% of all workers using the December 2020 definitions. As a whole, educators are more female (72\%), more white (72\%), and more educated (81\% hold a BA or higher) than the labor force as a whole as well as other essential and frontline workers (Table 3, Panel A). The well-above average percent female is driven by the large share who are employees in primary and secondary schools, 78\% of whom are female. Educators earn average wages overall and have a lower than average share of low wage workers, with workers in colleges, universities, and professional schools earning well above average wages.

\footnotetext{
${ }^{6}$ According to Dingel and Neiman (2020), 85 \% of educators can work from home, which would exclude them from our frontline definition of $33 \%$ of workers being unable to work home. We nonetheless include them in our December 2020 frontline worker group because at that time many were teaching in person and were required to do so. As of March 8, 2021, K-12 educators were officially eligible for vaccination in all U.S. states (Robertson 2021). ${ }^{7}$ Overall, workers in education occupations constitute $56.3 \%$ of employees in the education sector.
} 


\section{ESSENTIAL AND FRONTLINE: DECEMBER 2020}

Table 4 replicates Panel A from Tables 1 and 2 adding the group averages for December 2020 essential and frontline workers for comparison. ${ }^{8}$ The main difference between the December and earlier March definitions is the inclusion of the education sector. As mentioned above, we do not include shutdown versions of the December definitions. December essential workers make up an even larger share (82\%) of the entire workforce and continue to have demographic and labor market characteristics that are almost identical to all workers. Because educators are highly educated, the main difference between March frontline workers and December frontline workers is that $26 \%$ of December frontline workers hold a BA or higher while this was true of only $19 \%$ of March frontline workers. Overall, however, frontline workers remain less well educated than all workers, with a higher share of workers without a high school degree and a lower share with a BA or higher. The inclusion of workers in the education sector also increases the share of frontline workers who are female, from 39 to 43 percent, but this remains below the female share of all workers. While there are some differences, our overall conclusions regarding the composition of frontline workers remain the same using the December definitions: frontline workers are, on average, a less educated group, with a higher representation of men, disadvantaged minorities (especially Hispanics), and immigrants, and are lower paid than all workers with a larger share in the low wage quartile.

\section{OTHER ESTIMATES}

As noted above, the DHS guidelines must be interpreted to translate them into industry codes. In this section, we briefly compare our results to two other studies that provide estimates of essential workers by interpreting the guidelines: Tomer and Kane (2020) and Kearney and

\footnotetext{
${ }^{8}$ Table A1 shows the share of December frontline for each occupation group, including education occupations.
} 
Pardue (2020). ${ }^{9}$ Tomer and Kane (2020) estimate that 34\% to $43 \%$ of the overall workforce may be deemed essential. While notably lower than our estimate of essential workers, their definition is similar to what we call frontline workers, who make up $42.8 \%$ of the total workforce (frontline excluding shutdown makes up 33.7\%, similar to the lower bound of their estimate). In addition to excluding several manufacturing industries that we include, Tomer and Kane (2020) additionally exclude restaurants and food services, child care services, agricultural industries, and military that are described as essential by DHS though may not be fully operational. Like our frontline results, they find these workers face larger risk due to work environments requiring close proximity but earn lower wages and are less likely to have health insurance.

Kearney and Pardue (2020) estimate that 53\% of the overall workforce are essential workers. Using our data and their essential industry classification, $63 \%$ of the overall workforce would be deemed essential. Their estimate is similar to our "essential excluding shutdown" measure which makes up 59.5\% of the overall workforce. Like our shutdown definition, Kearney and Pardue exclude food services and traveler accommodations. Also in line with our analysis, they find that essential workers are very similar to the overall labor force, but this is not the case when divided by ability to work from home. Those working in person are disproportionately lower wage, less educated, and non-white workers just as our frontline workers are.

Overall, despite the difficulty to clearly identify essential workers due to the broad language used in the guidelines, we believe our measure of essential workers as well as our stepwise approach narrowing down to frontline workers provides the most complete picture to study those differentially impacted by in person work and exposure to the virus. Additionally, to the best of our knowledge, our paper is first to update results as the guidelines have evolved.

\footnotetext{
${ }^{9}$ Both studies have publicly shared their coding definitions for replication.
} 


\section{DISCUSSION AND CONCLUSION}

During the course of COVID-19, we relied on a subset of essential workers to meet our basic needs while significant portions of the population isolated at home. While some essential workers could themselves work from home, this was not feasible for a significant share of people, whom we designate as frontline workers, who must take on considerable risk to do their jobs. Although there is variation within this group, we have found that frontline workers are disproportionately comprised of less educated and disadvantaged minority workers, especially Hispanics, and immigrants, and earn below average wages, with a substantial share of workers in the bottom wage quartile. These workers, even healthcare workers, now face much higher risks than traditionally incurred in these occupations. Identifying essential and frontline workers and understanding their characteristics is useful for policymakers in targeting social insurance, personal protective equipment, and vaccine distribution in response to the COVID-19 crisis and researchers estimating the impact of the pandemic on different groups. 


\section{References}

Blau, F.D., Koebe, J., and Meyerhofer, P. (2020). Essential and Frontline Workers in the COVID-19 Crisis. Econofact. https://econofact.org/essential-and-frontline-workers-in-the-covid19-crisis Last accessed: August 24, 2020.

Department of Homeland Security. (2020). Guidance on the Essential Critical Infrastructure Workforce: Ensuring Community and National Resilience in COVID-19 Response Version 2.0. [electronic resource]. https://www.cisa.gov/sites/default/files/publications/CISA_Guidance_on_the_Essential_Critical_ Infrastructure_Workforce_Version_2.0_1.pdf Last accessed: March 3, 2021.

Department of Homeland Security. (2020). Guidance on the Essential Critical Infrastructure Workforce: Ensuring Community and National Resilience in COVID-19 Response Version 4.0. [electronic resource]. https://www.cisa.gov/sites/default/files/publications/ECIW_4.0_Guidance_on_Essential_Critical _Infrastructure_Workers_Final3_508_0.pdf Last accessed: March 3, 2021.

Dingel, J. I., and Neiman, B. (2020). How Many Jobs Can be Done at Home?, NBER Working Paper 26948.

Gupta, S., Montenovo, L., Nguyen, T.D., Rojas, F.L., Schmutte, I.M., Simon, K.I.. Weinberg, B.A, and Wing, C. (2020). Effects of Social Distancing Policy on Labor Market Outcomes. NBER Working Paper 27280.

Kearney, M. and Pardue, L. (2020). Exposure on the job: Who are the essential workers who likely cannot work from home? https://www.brookings.edu/research/exposure-on-the-job/ Last accessed: March 9, 2021.

Montenovo, L., Jiang, X., Rojas, F.L., Schmutte, I.M., Simon, K.I.. Weinberg, B.A, and Wing, C. (2020). Determinant of Disparities in COVID-19 Job Losses. NBER Working Paper 27132.

Robertson, C. (2021). “Teachers in all U.S. States are Now Eligible for Vaccination, Though There is Confusion in Some States.” The New York Times. https://www.nytimes.com/live/2021/03/08/world/covid-19coronavirus? referringSource=articleShare\#teachers-in-all-us-states-are-now-eligible-for-vaccinationthough-there-is-confusion-in-some-states Accessed: March 11, 2021

Ruggles, S., Flood, S., Goeken, R., Grover, J. Meyer, E., Pacas, J., and Sobek, M. IPUMS USA: Version 10.0 American Community Survey 2017-2018. Minneapolis, MN: IPUMS, 2020. https://doi.org/10.18128/D010.V10.0

Tomer, A. and Kane, J.W. (2020). How to protect essential workers during COVID-19. Brookings. https://www.brookings.edu/research/how-to-protect-essential-workers-during-covid19/\#footref-1 Last accessed: March 9, 2021. 
Vavra, J.S. (2020). Shutdown Sectors Represent Large Share of All US Employment. Becker Friedman Institute. https://bfi.uchicago.edu/insight/blog/key-economic-facts-about-covid19/\#shutdown-sectors Last accessed: August 24, 2020 


\begin{tabular}{|c|c|c|c|c|c|c|c|c|c|c|c|c|c|c|c|c|}
\hline \multicolumn{17}{|l|}{ Panel A: Group Averages } \\
\hline All & 0.47 & 0.62 & 0.12 & 0.18 & 0.06 & 0.03 & 0.19 & 0.08 & 0.09 & 0.24 & 0.31 & 0.35 & $3,042,378$ & & & \\
\hline Essential & 0.44 & 0.60 & 0.12 & 0.19 & 0.06 & 0.03 & 0.20 & 0.08 & 0.10 & 0.27 & 0.33 & 0.30 & $2,128,330$ & $70.0 \%$ & & \\
\hline Essential excl. Shutdown & 0.44 & 0.62 & 0.12 & 0.18 & 0.06 & 0.03 & 0.19 & 0.08 & 0.09 & 0.26 & 0.32 & 0.33 & $1,809,150$ & $59.5 \%$ & & \\
\hline Frontline & 0.39 & 0.57 & 0.13 & 0.22 & 0.05 & 0.03 & 0.22 & 0.08 & 0.14 & 0.33 & 0.34 & 0.19 & $1,301,854$ & $42.8 \%$ & & \\
\hline Frontline excl. Shutdown & 0.38 & 0.58 & 0.13 & 0.22 & 0.05 & 0.03 & 0.21 & 0.08 & 0.13 & 0.32 & 0.33 & 0.21 & $1,025,969$ & $33.7 \%$ & & \\
\hline \multicolumn{17}{|l|}{ Panel B: Frontline by Occupation Group } \\
\hline Healthcare Practitioners and Technical Occupations & 0.75 & 0.67 & 0.11 & 0.09 & 0.10 & 0.03 & 0.17 & 0.11 & 0.01 & 0.06 & 0.33 & 0.60 & 183,208 & & $14.1 \%$ & \\
\hline Healthcare Support & 0.86 & 0.45 & 0.25 & 0.20 & 0.07 & 0.03 & 0.24 & 0.23 & 0.10 & 0.31 & 0.46 & 0.13 & 81,774 & & $6.3 \%$ & \\
\hline Protective Service Occupations & 0.22 & 0.59 & 0.20 & 0.15 & 0.03 & 0.03 & 0.11 & 0.05 & 0.03 & 0.24 & 0.46 & 0.28 & 55,699 & & $4.3 \%$ & \\
\hline Food Preparation and Serving Occupations & 0.53 & 0.51 & 0.13 & 0.26 & 0.07 & 0.04 & 0.23 & 0.10 & 0.23 & 0.34 & 0.34 & 0.09 & 132,965 & & $10.2 \%$ & \\
\hline Building and Grounds Cleaning and Maintenance Occupation & 0.39 & 0.42 & 0.14 & 0.39 & 0.03 & 0.03 & 0.38 & 0.11 & 0.29 & 0.41 & 0.23 & 0.07 & 73,099 & & $5.6 \%$ & \\
\hline Personal Care and Service Occupations & 0.80 & 0.56 & 0.16 & 0.21 & 0.05 & 0.03 & 0.20 & 0.15 & 0.12 & 0.30 & 0.40 & 0.18 & 22,974 & & $1.8 \%$ & \\
\hline Sales and Related Occupations & 0.48 & 0.65 & 0.10 & 0.16 & 0.06 & 0.03 & 0.15 & 0.08 & 0.09 & 0.27 & 0.35 & 0.29 & 192,579 & & $14.8 \%$ & \\
\hline Farming, Fishing, and Forestry Occupations & 0.24 & 0.42 & 0.04 & 0.51 & 0.02 & 0.02 & 0.45 & 0.06 & 0.44 & 0.31 & 0.17 & 0.08 & 19,911 & & $1.5 \%$ & \\
\hline Construction and Extraction Occupations & 0.03 & 0.55 & 0.06 & 0.35 & 0.01 & 0.02 & 0.30 & 0.01 & 0.24 & 0.43 & 0.27 & 0.06 & 135,904 & & $10.4 \%$ & \\
\hline Installation, Maintenaince, and Repair Workers & 0.04 & 0.67 & 0.08 & 0.20 & 0.03 & 0.03 & 0.17 & 0.01 & 0.11 & 0.41 & 0.41 & 0.07 & 77,228 & & $5.9 \%$ & \\
\hline Production Occupations & 0.26 & 0.57 & 0.13 & 0.22 & 0.05 & 0.02 & 0.22 & 0.06 & 0.15 & 0.44 & 0.32 & 0.09 & 134,555 & & $10.3 \%$ & \\
\hline Transportation and Material Moving Occupations & 0.19 & 0.53 & 0.18 & 0.22 & 0.04 & 0.03 & 0.21 & 0.04 & 0.15 & 0.44 & 0.31 & 0.10 & 180,599 & & $13.9 \%$ & \\
\hline \multicolumn{17}{|l|}{ Panel C: Frontline excluding Shutdown by Occupation Group } \\
\hline Healthcare Practitioners and Technical Occupations & 0.75 & 0.67 & 0.12 & 0.09 & 0.10 & 0.03 & 0.17 & 0.11 & 0.01 & 0.06 & 0.33 & 0.60 & 175,294 & & & $17.1 \%$ \\
\hline Healthcare Support & 0.85 & 0.44 & 0.26 & 0.19 & 0.07 & 0.03 & 0.25 & 0.23 & 0.10 & 0.32 & 0.45 & 0.13 & 75,884 & & & $7.4 \%$ \\
\hline Protective Service Occupations & 0.21 & 0.59 & 0.19 & 0.15 & 0.03 & 0.03 & 0.10 & 0.05 & 0.02 & 0.23 & 0.46 & 0.29 & 54,278 & & & $5.3 \%$ \\
\hline Food Preparation and Serving Occupations & 0.62 & 0.53 & 0.19 & 0.19 & 0.06 & 0.03 & 0.20 & 0.14 & 0.18 & 0.40 & 0.33 & 0.08 & 16,630 & & & $1.6 \%$ \\
\hline Building and Grounds Cleaning and Maintenance Occupation & 0.35 & 0.44 & 0.13 & 0.39 & 0.02 & 0.02 & 0.37 & 0.10 & 0.29 & 0.41 & 0.24 & 0.07 & 63,202 & & & $6.2 \%$ \\
\hline Personal Care and Service Occupations & 0.83 & 0.57 & 0.15 & 0.21 & 0.04 & 0.03 & 0.20 & 0.16 & 0.12 & 0.30 & 0.40 & 0.18 & 21,126 & & & $2.1 \%$ \\
\hline Sales and Related Occupations & 0.47 & 0.68 & 0.09 & 0.15 & 0.05 & 0.03 & 0.15 & 0.08 & 0.07 & 0.26 & 0.36 & 0.32 & 169,471 & & & $16.5 \%$ \\
\hline Farming, Fishing, and Forestry Occupations & 0.24 & 0.42 & 0.04 & 0.51 & 0.02 & 0.02 & 0.45 & 0.06 & 0.44 & 0.31 & 0.17 & 0.08 & 19,888 & & & $1.9 \%$ \\
\hline Construction and Extraction Occupations & 0.03 & 0.55 & 0.06 & 0.36 & 0.01 & 0.02 & 0.30 & 0.01 & 0.24 & 0.43 & 0.27 & 0.06 & 134,048 & & & $13.1 \%$ \\
\hline Installation, Maintenaince, and Repair Workers & 0.04 & 0.67 & 0.08 & 0.20 & 0.03 & 0.03 & 0.16 & 0.01 & 0.11 & 0.41 & 0.40 & 0.07 & 68,626 & & & $6.7 \%$ \\
\hline Production Occupations & 0.26 & 0.57 & 0.12 & 0.23 & 0.06 & 0.02 & 0.23 & 0.06 & 0.16 & 0.43 & 0.32 & 0.09 & 112,688 & & & $11.0 \%$ \\
\hline Transportation and Material Moving Occupations & 0.17 & 0.54 & 0.17 & 0.23 & 0.03 & 0.03 & 0.19 & 0.04 & 0.16 & 0.46 & 0.30 & 0.07 & 139,722 & & & $13.6 \%$ \\
\hline
\end{tabular}

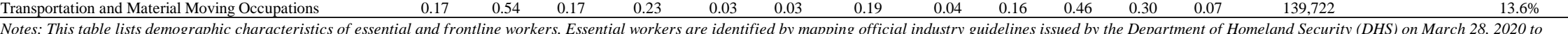
microdata from the 2018 and 2019 American Community Survey. Frontline workers are approximated by their feasibility of work from home in the worker's occupation group (Dingel and Neiman 2020). Shutdown adjusts for industries that were shutdown or running under limited demand early in the COVID crisis (Vavra 2020). Group averages are shown in Panel A. Panel B reports demographic characteristics at the major (2-digit) occupation group level for frontline workers, while Panel C additionally excludes shutdown industries. Demographic charateristics consist of the share of females, racial background (White, Black, Hispanic, Asian, Other Race, immigrant status (foreign born), single mother, and highest educational attainment (less than High-School (HS), HS degree, some college, higher than Bachelor Degree (BA). Military is excluded as an occupation group, so share does not sum to 100. 
Table 2: Labor Market Characteristics of Essential and Frontline Workers: March 2020

\begin{tabular}{|c|c|c|c|c|c|c|c|c|c|}
\hline & $\begin{array}{l}\text { Female } \\
\text { Dominated } \\
\text { Occ }\end{array}$ & $\begin{array}{l}\text { Male } \\
\text { Dominated } \\
\text { Occ }\end{array}$ & $\begin{array}{c}\text { Hourly } \\
\text { wages } \\
(\$)\end{array}$ & $\begin{array}{c}\% \text { Low } \\
\text { Wage }\end{array}$ & $\begin{array}{l}\text { \% High } \\
\text { Wage }\end{array}$ & $\mathrm{N}$ & $\%$ All & \% Frontline & $\begin{array}{l}\text { excl. } \\
\text { Shutdown }\end{array}$ \\
\hline \multicolumn{10}{|l|}{ Panel A: Group Averages } \\
\hline All & 0.28 & 0.30 & $\$ 27.05$ & 0.25 & 0.25 & $3,042,378$ & & & \\
\hline Essential & 0.26 & 0.35 & $\$ 27.10$ & 0.24 & 0.25 & $2,128,330$ & $70.0 \%$ & & \\
\hline Essential excl. Shutdown & 0.26 & 0.37 & $\$ 28.42$ & 0.22 & 0.27 & $1,809,150$ & $59.5 \%$ & & \\
\hline Frontline & 0.26 & 0.44 & $\$ 22.76$ & 0.30 & 0.18 & $1,301,854$ & $42.8 \%$ & & \\
\hline Frontline excl. Shutdown & 0.24 & 0.48 & $\$ 24.00$ & 0.27 & 0.20 & $1,025,969$ & $33.7 \%$ & & \\
\hline \multicolumn{10}{|l|}{ Panel B: Frontline by Occupation Group } \\
\hline Healthcare Practitioners and Technical Occupations & 0.70 & 0.04 & $\$ 41.30$ & 0.09 & 0.47 & 183,208 & & $14.1 \%$ & \\
\hline Healthcare Support & 0.99 & 0.00 & $\$ 16.33$ & 0.36 & 0.06 & 81,774 & & $6.3 \%$ & \\
\hline Protective Service Occupations & 0.01 & 0.92 & $\$ 27.96$ & 0.14 & 0.30 & 55,699 & & $4.3 \%$ & \\
\hline Food Preparation and Serving Occupations & 0.30 & 0.09 & $\$ 13.31$ & 0.53 & 0.04 & 132,965 & & $10.2 \%$ & \\
\hline Building and Grounds Cleaning and Maintenance Occupation & 0.24 & 0.31 & $\$ 14.23$ & 0.48 & 0.06 & 73,099 & & $5.6 \%$ & \\
\hline Personal Care and Service Occupations & 0.68 & 0.05 & $\$ 12.75$ & 0.57 & 0.05 & 22,974 & & $1.8 \%$ & \\
\hline Sales and Related Occupations & 0.26 & 0.14 & $\$ 26.11$ & 0.34 & 0.22 & 192,579 & & $14.8 \%$ & \\
\hline Farming, Fishing, and Forestry Occupations & 0.00 & 0.93 & $\$ 14.30$ & 0.47 & 0.05 & 19,911 & & $1.5 \%$ & \\
\hline Construction and Extraction Occupations & 0.00 & 1.00 & $\$ 20.85$ & 0.28 & 0.18 & 135,904 & & $10.4 \%$ & \\
\hline Installation, Maintenaince, and Repair Workers & 0.00 & 1.00 & $\$ 23.64$ & 0.18 & 0.22 & 77,228 & & $5.9 \%$ & \\
\hline Production Occupations & 0.00 & 0.50 & $\$ 20.97$ & 0.20 & 0.14 & 134,555 & & $10.3 \%$ & \\
\hline Transportation and Material Moving Occupations & 0.01 & 0.78 & $\$ 19.69$ & 0.31 & 0.11 & 180,599 & & $13.9 \%$ & \\
\hline \multicolumn{10}{|l|}{ Panel C: Frontline excluding Shutdown by Occupation Group } \\
\hline Healthcare Practitioners and Technical Occupations & 0.71 & 0.02 & $\$ 40.63$ & 0.09 & 0.47 & 175,294 & & & $17.1 \%$ \\
\hline Healthcare Support & 0.98 & 0.00 & $\$ 16.10$ & 0.37 & 0.05 & 75,884 & & & $7.4 \%$ \\
\hline Protective Service Occupations & 0.00 & 0.93 & $\$ 28.20$ & 0.13 & 0.31 & 54,278 & & & $5.3 \%$ \\
\hline Food Preparation and Serving Occupations & 0.05 & 0.10 & $\$ 14.22$ & 0.48 & 0.03 & 16,630 & & & $1.6 \%$ \\
\hline Building and Grounds Cleaning and Maintenance Occupation & 0.19 & 0.36 & $\$ 14.16$ & 0.48 & 0.06 & 63,202 & & & $6.2 \%$ \\
\hline Personal Care and Service Occupations & 0.73 & 0.05 & $\$ 12.39$ & 0.59 & 0.05 & 21,126 & & & $2.1 \%$ \\
\hline Sales and Related Occupations & 0.20 & 0.15 & $\$ 27.76$ & 0.31 & 0.24 & 169,471 & & & $16.5 \%$ \\
\hline Farming, Fishing, and Forestry Occupations & 0.00 & 0.93 & $\$ 14.30$ & 0.47 & 0.05 & 19,888 & & & $1.9 \%$ \\
\hline Construction and Extraction Occupations & 0.00 & 1.00 & $\$ 20.77$ & 0.28 & 0.17 & 134,048 & & & $13.1 \%$ \\
\hline Installation, Maintenaince, and Repair Workers & 0.00 & 1.00 & $\$ 23.20$ & 0.19 & 0.21 & 68,626 & & & $6.7 \%$ \\
\hline Production Occupations & 0.00 & 0.52 & $\$ 20.88$ & 0.20 & 0.14 & 112,688 & & & $11.0 \%$ \\
\hline Transportation and Material Moving Occupations & 0.00 & 0.79 & $\$ 18.80$ & 0.29 & 0.10 & 139,722 & & & $13.6 \%$ \\
\hline \multicolumn{10}{|c|}{$\begin{array}{l}\text { Notes: This table lists labor market characteristics of essential and frontline workers. Essential workers are identified by mapping official industry guidelines issued by the } \\
\text { Department of Homeland Security (DHS) on March 28, } 2020 \text { to microdata from the } 2018 \text { and } 2019 \text { American Community Survey. Frontline workers are approximated by their } \\
\text { feasibility of work from home in the worker's occupation group (Dingel and Neiman 2020). Shutdown adjusts for industries that were shutdown or running under limited demand } \\
\text { early in the COVID crisis (Vavra 2020). Group averages are shown in Panel A. Panel B reports labor market characteristics at the major (2-digit) occupation group level for } \\
\text { frontline workers, while Panel C additionally excludes shutdown industries. Labor market charateristics consist of the share of females, share of workers that work in } \\
\text { predominantly female 4-digit occupations (70 percent or more of workers are female) or predominantly male 4-digit occupations ( } 30 \text { percent or less of the workers are female), } \\
\text { hourly wages (income in } 2019 \text { dollars using the CPI divided by the product of usual hours worked per week and the mid-point of usual weeks worked per year), share of workers } \\
\text { earning low wages (in the bottom quartile of the overall wage distribution) and high wages (in the top quartile of the overall wage distribution). Military is excluded as an }\end{array}$} \\
\hline
\end{tabular}


Table 3: Demographic and Labor Market Characteristics of Workers in Education Occupations (within Education Sector)

Panel A: Education Demographics by Industry

\begin{tabular}{|c|c|c|c|c|c|c|c|c|c|c|c|c|}
\hline & $\%$ Female & $\%$ White & $\%$ Black & \% Hispanic & $\%$ Asian & $\begin{array}{l}\text { \% Other } \\
\text { Race }\end{array}$ & \% Immigrant & $\begin{array}{l}\text { \% Single } \\
\text { Mother }\end{array}$ & $\%<\mathrm{HS}$ & $\% \mathrm{HS}$ & $\begin{array}{l}\text { \% Some } \\
\text { College }\end{array}$ & $\begin{array}{c}\% \text { BA or } \\
\text { higher }\end{array}$ \\
\hline Education & 0.72 & 0.72 & 0.09 & 0.11 & 0.06 & 0.03 & 0.14 & 0.08 & 0.01 & 0.05 & 0.13 & 0.81 \\
\hline Elementary and secondary schools & 0.78 & 0.73 & 0.10 & 0.12 & 0.03 & 0.02 & 0.10 & 0.09 & 0.01 & 0.05 & 0.12 & 0.82 \\
\hline Colleges, universities, and professional schools & 0.51 & 0.69 & 0.07 & 0.08 & 0.14 & 0.03 & 0.24 & 0.03 & 0.01 & 0.02 & 0.11 & 0.86 \\
\hline Business, technical, and trade schools and training & 0.57 & 0.74 & 0.07 & 0.11 & 0.05 & 0.03 & 0.14 & 0.06 & 0.02 & 0.14 & 0.32 & 0.52 \\
\hline Other schools and instruction, and educational support services & 0.67 & 0.69 & 0.07 & 0.11 & 0.10 & 0.03 & 0.16 & 0.05 & 0.05 & 0.09 & 0.24 & 0.62 \\
\hline \multicolumn{13}{|l|}{ Panel B: Education Labor Market Characteristics by Industry } \\
\hline & $\begin{array}{c}\text { Female } \\
\text { Dominated } \\
\text { Occ }\end{array}$ & $\begin{array}{c}\text { Male } \\
\text { Dominated } \\
\text { Occ }\end{array}$ & $\begin{array}{c}\text { Hourly } \\
\text { wages (\$) }\end{array}$ & $\begin{array}{l}\text { \% Low } \\
\text { Wage }\end{array}$ & $\begin{array}{l}\text { \% High } \\
\text { Wage }\end{array}$ & $\mathrm{N}$ & $\%$ All & \% Frontline & & & & \\
\hline Education & 0.64 & 0.00 & $\$ 27.96$ & 0.17 & 0.27 & 174,602 & $5.7 \%$ & $13.4 \%$ & & & & \\
\hline Elementary and secondary schools & 0.82 & 0.00 & $\$ 26.59$ & 0.15 & 0.24 & 128,327 & $4.2 \%$ & $9.9 \%$ & & & & \\
\hline Colleges, universities, and professional schools & 0.13 & 0.00 & $\$ 35.46$ & 0.16 & 0.40 & 36,651 & $1.2 \%$ & $2.8 \%$ & & & & \\
\hline Business, technical, and trade schools and training & 0.19 & 0.00 & $\$ 26.72$ & 0.23 & 0.28 & 923 & $0.0 \%$ & $0.1 \%$ & & & & \\
\hline Other schools and instruction, and educational support services & 0.10 & 0.00 & $\$ 17.63$ & 0.49 & 0.13 & 8,701 & $0.3 \%$ & $0.7 \%$ & & & & \\
\hline
\end{tabular}

Notes: This table lists demographic and occupational characteristics of educators (those in NAICS industries 7860, 7870, 7880, and 7890 with occupation code between 2200 and 2555 ). Demographic charateristics consist of the share of females, racial background (White, Black, Hispanic, Asian, Other Race, immigrant status (foreign born), single mother, and highest educational attainment (less than High-School (HS), HS degree, some college, higher than Bachelor Degree (BA). Labor market charateristics consist of the share of females, share of workers that work in predominantly female 4-digit occupations (70 percent or more of workers are female) or predominantly male 4-digit occupations (30 percent or less of the workers are female), hourly wages (income in 2019 dollars using the CPI divided by the product of usual hours worked per week and the mid-point of usual weeks worked per year), share of workers earning low wages (in the bottom quartile of the overall wage distribution) and high wages (in the top quartile of the overall wage distribution). 
Table 4: Demographic and Labor Market Characteristics of Essential and Frontline Workers March v. December 2020 Panel A: Demographic Characteristics by Group

\begin{tabular}{|c|c|c|c|c|c|c|c|c|c|c|c|c|}
\hline & $\%$ Female & $\%$ White & $\%$ Black & \% Hispanic & $\%$ Asian & $\begin{array}{c}\text { \% Other } \\
\text { Race }\end{array}$ & $\begin{array}{c}\% \\
\text { Immigrant }\end{array}$ & $\begin{array}{c}\text { \% Single } \\
\text { Mother }\end{array}$ & $\%<\mathrm{HS}$ & $\% \mathrm{HS}$ & $\begin{array}{l}\text { \% Some } \\
\text { College }\end{array}$ & $\begin{array}{c}\% \text { BA or } \\
\text { higher }\end{array}$ \\
\hline All & 0.47 & 0.62 & 0.12 & 0.18 & 0.06 & 0.03 & 0.19 & 0.08 & 0.09 & 0.24 & 0.31 & 0.35 \\
\hline March 2020- Essential & 0.44 & 0.60 & 0.12 & 0.19 & 0.06 & 0.03 & 0.20 & 0.08 & 0.10 & 0.27 & 0.33 & 0.30 \\
\hline March 2020 - Essential excl. Shutdown & 0.44 & 0.62 & 0.12 & 0.18 & 0.06 & 0.03 & 0.19 & 0.08 & 0.09 & 0.26 & 0.32 & 0.33 \\
\hline March 2020- Frontline & 0.39 & 0.57 & 0.13 & 0.22 & 0.05 & 0.03 & 0.22 & 0.08 & 0.14 & 0.33 & 0.34 & 0.19 \\
\hline March 2020 - Frontline excl. Shutdown & 0.38 & 0.58 & 0.13 & 0.22 & 0.05 & 0.03 & 0.21 & 0.08 & 0.13 & 0.32 & 0.33 & 0.21 \\
\hline December 2020 - Essential & 0.46 & 0.62 & 0.12 & 0.18 & 0.06 & 0.03 & 0.19 & 0.08 & 0.09 & 0.25 & 0.31 & 0.34 \\
\hline December 2020 - Frontline & 0.43 & 0.58 & 0.13 & 0.21 & 0.05 & 0.03 & 0.21 & 0.08 & 0.13 & 0.30 & 0.32 & 0.26 \\
\hline \multicolumn{13}{|c|}{ Panel B: Occupational Characteristics by Group } \\
\hline & $\begin{array}{c}\text { Female } \\
\text { Dominated } \\
\text { Occ }\end{array}$ & $\begin{array}{c}\text { Male } \\
\text { Dominated } \\
\text { Occ }\end{array}$ & $\begin{array}{c}\text { Hourly } \\
\text { wages (\$) }\end{array}$ & $\begin{array}{l}\% \text { Low } \\
\text { Wage }\end{array}$ & $\begin{array}{l}\text { \% High } \\
\text { Wage }\end{array}$ & $\mathrm{N}$ & $\%$ All & & & & & \\
\hline All & 0.28 & 0.30 & $\$ 27.05$ & 0.25 & 0.25 & $3,042,378$ & & & & & & \\
\hline March 2020 - Essential & 0.26 & 0.35 & $\$ 27.10$ & 0.24 & 0.25 & $2,128,330$ & $70.0 \%$ & & & & & \\
\hline March 2020 - Essential excluding Shutdow] & 0.26 & 0.37 & $\$ 28.42$ & 0.22 & 0.27 & $1,809,150$ & $59.5 \%$ & & & & & \\
\hline March 2020 - Frontline & 0.26 & 0.44 & $\$ 22.76$ & 0.30 & 0.18 & $1,301,854$ & $42.8 \%$ & & & & & \\
\hline March 2020 - Frontline excluding Shutdow. & 0.24 & 0.48 & $\$ 24.00$ & 0.27 & 0.20 & $1,025,969$ & $33.7 \%$ & & & & & \\
\hline December 2020 - Essential & 0.28 & 0.31 & $\$ 27.03$ & 0.24 & 0.25 & $2,481,637$ & $81.6 \%$ & & & & & \\
\hline December 2020 - Frontline & 0.29 & 0.38 & $\$ 23.16$ & 0.29 & 0.19 & $1,578,959$ & $51.9 \%$ & & & & & \\
\hline
\end{tabular}

Notes: This table lists demographic and occupational characteristics of essential and frontline workers. Essential workers are identified by mapping official industry guidelines issued by the Department of Homeland Security (DHS) on March 28, 2020 and December 16, 2020 to microdata from the 2018 and 2019 American Community Survey. Frontline workers are approximated by their feasibility of work from home in the worker's occupation group (Dingel and Neiman 2020). Shutdown adjusts for industries that were shutdown or running under limited demand early in the COVID crisis (Vavra 2020). Demographic charateristics consist of the share of females, racial background (White, Black, Hispanic, Asian, Other Race, immigrant status (foreign born), single mother, and highest educational attainment (less than High-School (HS), HS degree, some college, higher than Bachelor Degree (BA). Labor market charateristics consist of the share of females, share of workers that work in predominantly female 4-digit occupations (70 percent or more of workers are female) or predominantly male 4-digit occupations (30 percent or less of the workers are female), hourly wages (income in 2019 dollars using the CPI divided by the product of usual hours worked per week and the mid-point of usual weeks worked per year), share of workers earning low wages (in the bottom quartile of the overall wage distribution) and high wages (in the top quartile of the overall wage distribution). Military is excluded as an occupation group, so share does not sum to 100. 
Table A1. Occupation Group as Share of December 2020 Frontline

\begin{tabular}{lcc}
\hline Occupation Group & $\mathrm{N}$ & $\begin{array}{c}\% \text { Dec } \\
\text { Frontline }\end{array}$ \\
\hline Education Occupations & 194,281 & $12.3 \%$ \\
Healthcare Practitioners and Technical Occupations & 191,311 & $12.1 \%$ \\
Healthcare Support & 82,599 & $5.2 \%$ \\
Protective Service Occupations & 58,607 & $3.7 \%$ \\
Food Preparation and Serving Occupations & 140,681 & $8.9 \%$ \\
Building and Grounds Cleaning and Maintenance Occupations & 84,698 & $5.4 \%$ \\
Personal Care and Service Occupations & 30,429 & $1.9 \%$ \\
Sales and Related Occupations & 212,110 & $13.4 \%$ \\
Farming, Fishing, and Forestry Occupations & 20,006 & $1.3 \%$ \\
Construction and Extraction Occupations & 137,182 & $8.7 \%$ \\
\hline Installation, Maintenaince, and Repair Workers & 85,846 & $5.4 \%$ \\
Production Occupations & 137,013 & $8.7 \%$ \\
\hline Transportation and Material Moving Occupations & 192,837 & $12.2 \%$ \\
\hline Notes: This table lists count of frontline workers by & . & \\
\hline
\end{tabular}

Notes: This table lists count of frontline workers by occupational group and share of

December Frontline workers. Essential workers are identified by mapping official industry guidelines issued by the Department of Homeland Security (DHS) on December 16, 2020

to microdata from the 2018 and 2019 American Community Survey. Frontline workers are approximated by their feasibility of work from home in the worker's occupation group

(Dingel and Neiman 2020). Military is excluded as an occupation group, so share does not sum to 100 . 